$$
\begin{aligned}
& \text { تقييم أداع مادة الزجاج المكسر ومادة الرمل كوسطي ترشيح في تصفية مياه الثرب }
\end{aligned}
$$

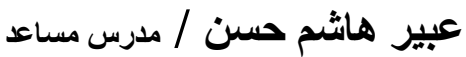

$$
\begin{aligned}
& \text { جامعة الموصل/كلية الهندسة / قسم الهندسة البيئية } \\
& \text { الخلاصة الخندة }
\end{aligned}
$$

تناول البحث تقييم أداء مادة الزجاج المكسر (Crushed glass) كوسط للترشيح مع مادة الرمل اعتماداً على تغاير كل

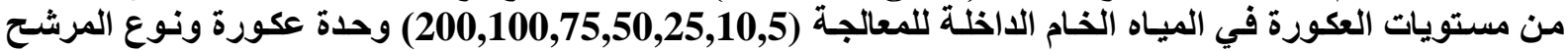

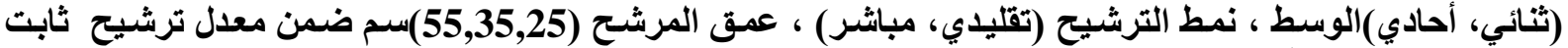

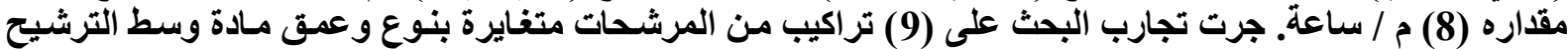

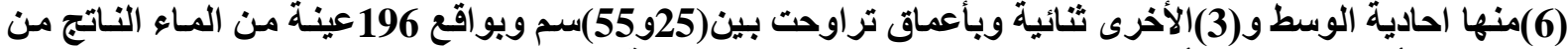

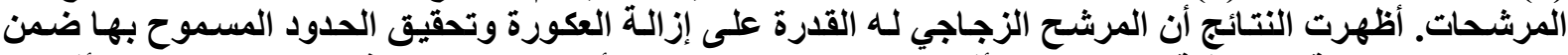

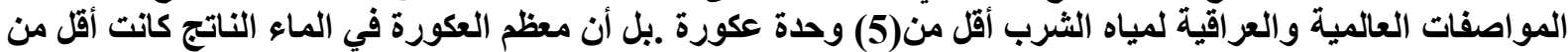

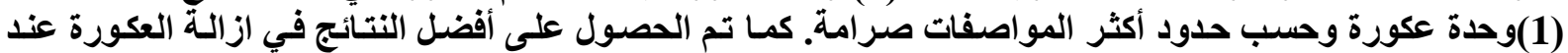

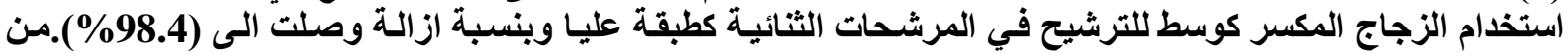

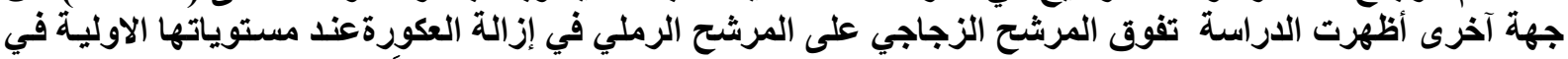

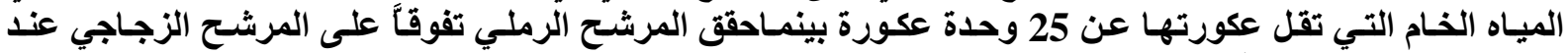

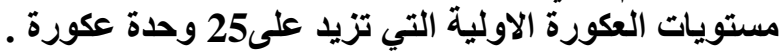
الكلمات المفتاحية : وسط الترشيح ، الزجاج المكسر، معدل الترشيح ، الترشيح المباشر ، المرشح الأحادي والثنائي.

\title{
Performance of using crushed glass and sand as a filtration media in purification drinking water
}

Abeer Hashim Hassan / Assist. Lecture

University of Mosul / College of Engineering / Environmental Engineering

\begin{abstract}
This research includes performance of using crushed glass as a filtration media with sand depending on the variation in turbidity levels in the raw water $(5,10,25,50,75,100$ and 200$)$ turbidity unit, type of the filter, type of filtration and the depth of the filter $(25,35$ and $55 \mathrm{~cm}$.) within filtration rate $(8) \mathrm{m} / \mathrm{hr}$. A total of (9) different configuration filters with different types and different depths of the filtration media, (6) of them are single-media and (3) are dual media which ranged between (25 and 55) $\mathrm{cm}$ and the number of the samples was (196) of the water resulting from the filters. The results showed that the glass media has the capability to remove turbidity and provide quality effluents conform to international and Iraqi specifications (less than 5 NTU).Effluent turbidity well below (1 NTU) is also achieved. In addition to that, the best results were obtained of removing turbidity when using the crushed glass as a filtration media in the dual filters as upper layer and with a removal percentage that reached $(\mathbf{9 8 . 4 \%})$. For the single filters, the study showed the superiority of the glass filter over the sand filter in terms of turbidity removal at the preliminary levels in raw water in which turbidity is less than (25 NTU). While the sand filter was superior over the glass one in turbidity levels which exceed (25 NTU).
\end{abstract}

Keyword: filtration media, crushed glass, filtration rate, direct filtration, single\& dual filters 
تعد وحدات الترشيح من أهم الوحدات في محطات تصفية الماء لكونها آخر مرحلة في عملية معالجة الأبة المياه الخـام

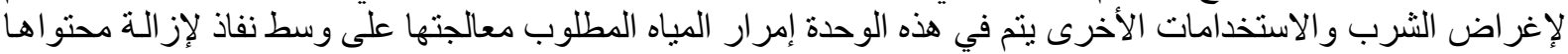

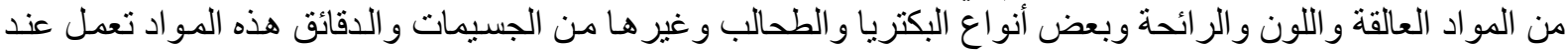

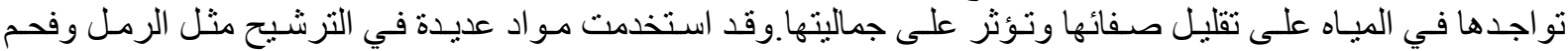

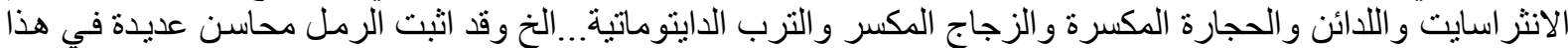

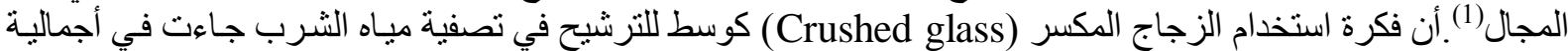

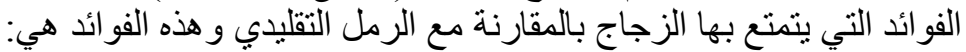

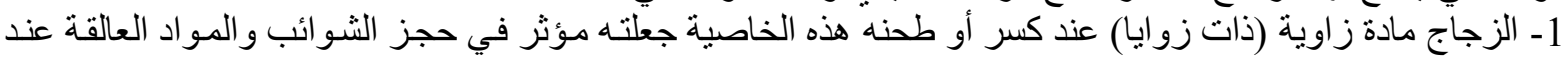

استخدامه كوسط للترشيح.

2- الزجاج لا يتشبع بالماء مقارنة مع الرجنة الرمل التقليدي أب أنه لا يشكل كتلة مرصوصة (حجمه ثابت داخل المرشح).

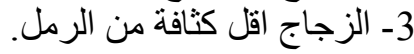

الخواص الكيماوية للزجاج

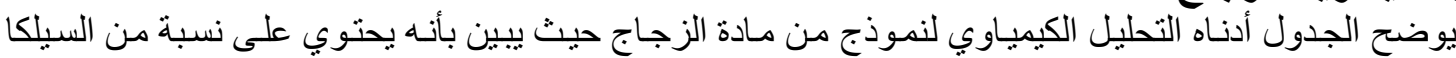

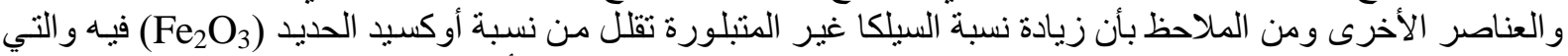
تعد معيار ا مهما في تحديد جودة المادة كونها تؤثر على صفادة الثبات الكيمياوي الأساسية في استخدام مـادة الزجاج كمادة

وسط للترشيح . تصنيا في

\begin{tabular}{|c|c|c|}
\hline & & للزجا: \\
\hline & الاكاسبيد & $\%$ \\
\hline السيلكا & $\overline{\mathrm{SiO}_{2}}$ & $\overline{\% 74}$ \\
\hline اوكسيد الصوديوم & $\mathrm{Na}_{2} \mathrm{O}$ & $\% 13$ \\
\hline أوكسبد الكالسيوم & $\mathrm{CaO}$ & $\% 10.5$ \\
\hline اوكسيد الالمنيوم & $\mathbf{A l}_{2} \mathrm{O}_{3}$ & $\% 1.3$ \\
\hline اوكسيد البوتاسيوم & $\mathrm{K}_{2} \mathrm{O}$ & $\% 0.3$ \\
\hline كبريتيدات & $\mathrm{SO}_{3}$ & $\% 0.2$ \\
\hline اوكسيد المغنسيوم & Mgo & $\% 0.2$ \\
\hline اوكسيد الحديد & $\mathrm{Fe}_{2} \mathrm{O}_{3}$ & $\% 0.04$ \\
\hline أوكسيد التيتانيوم & $\mathrm{TiO}_{2}$ & $\% 0.01$ \\
\hline
\end{tabular}

الترشيح المباشر

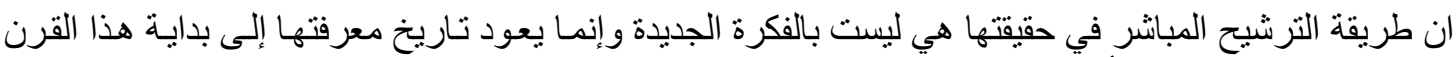

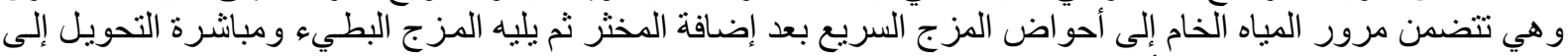

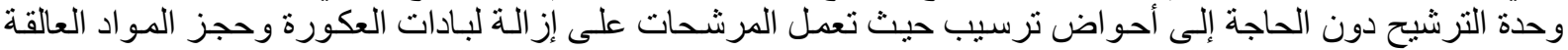

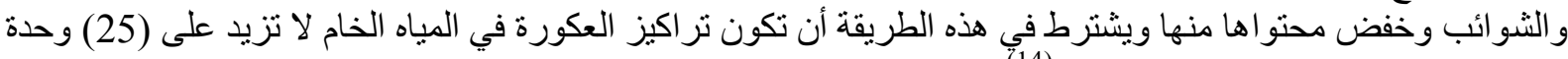

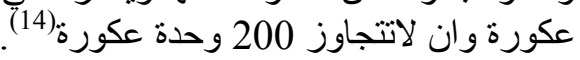

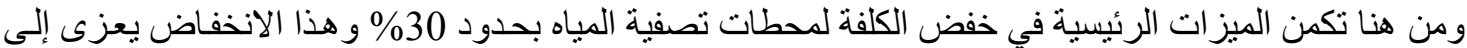

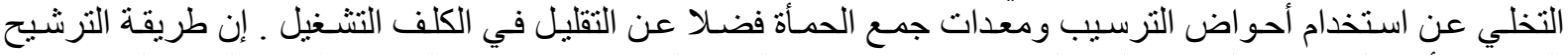

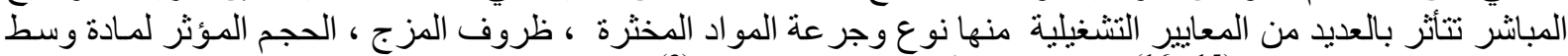

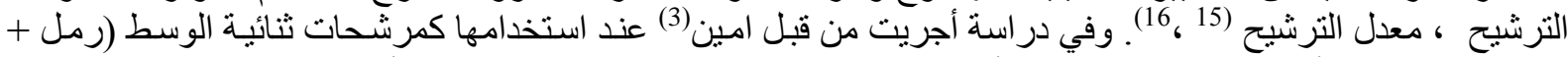

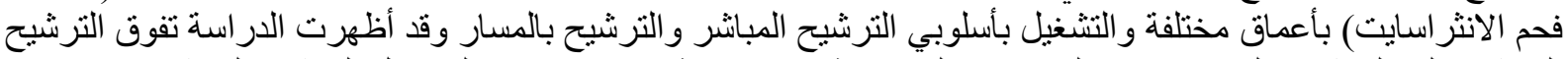

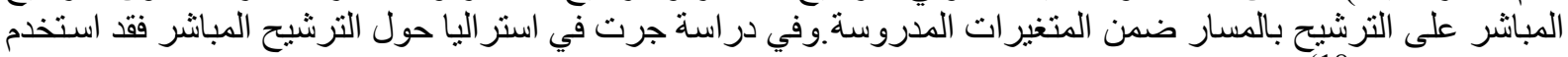

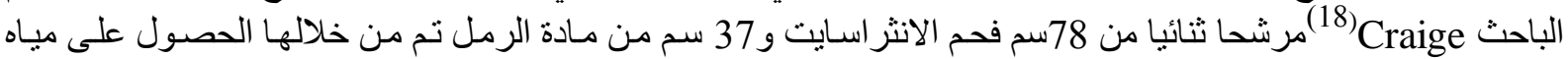
لاتزيد فيها العكورة عن 0.5 وحدة عكورة وقد استخدم الباحث الثب مادة رئيسية للتخثير. 


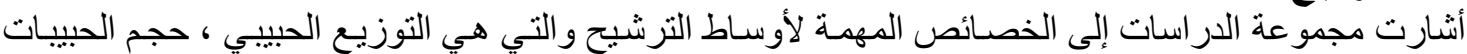

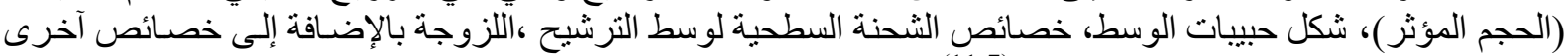
للوسط كلها تؤثر على كفاءة عملية الترشيح (11، (11).

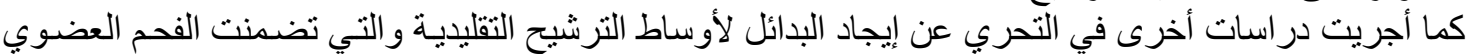

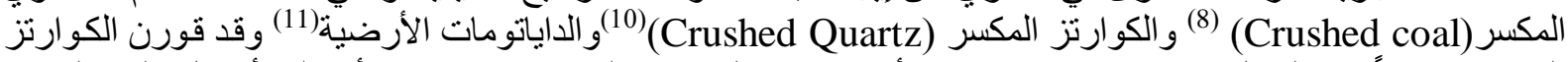

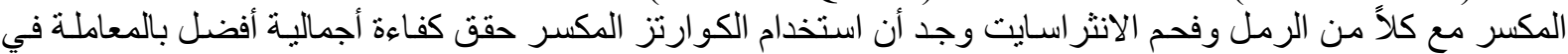

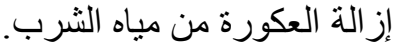

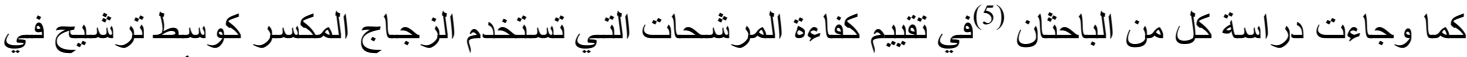

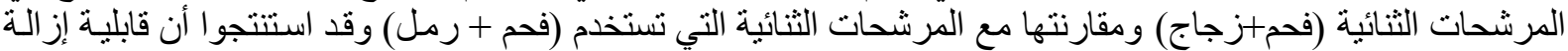

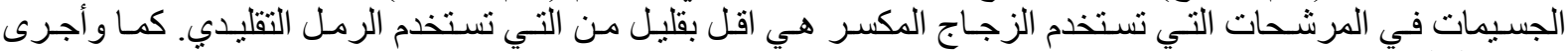

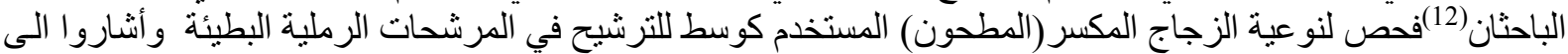

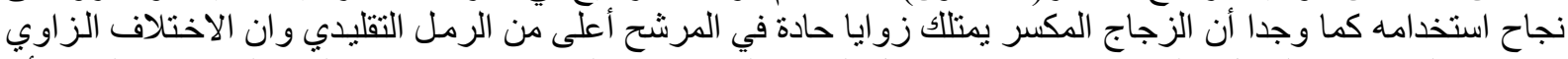

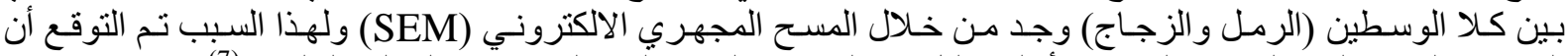

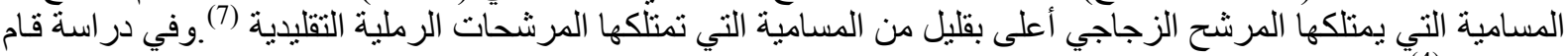

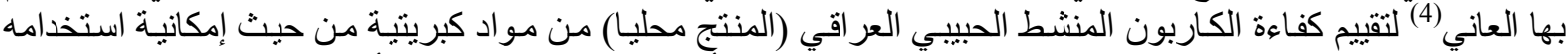

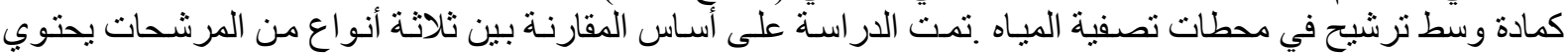

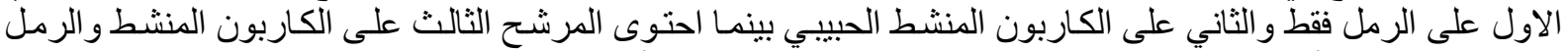

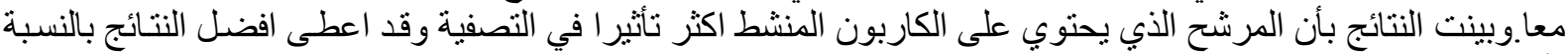

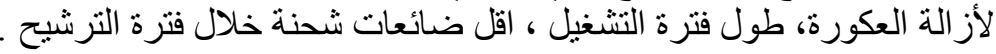

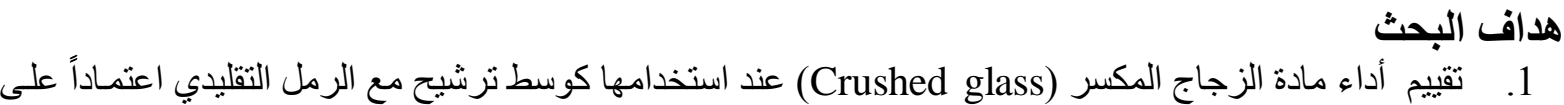

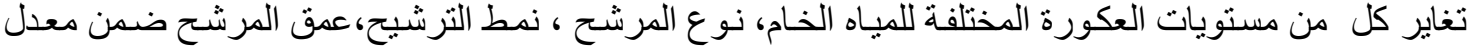

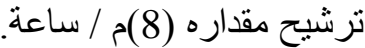
2. التحقق من كفاءة أداء طريقتي الترشيح التقليدي و المبانشر للتر اكيب المختلفة من المرشحات.

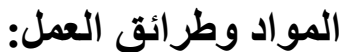

اعتمد هذا البحث في تحقيق أهدافه على استخدام المواد التالية:

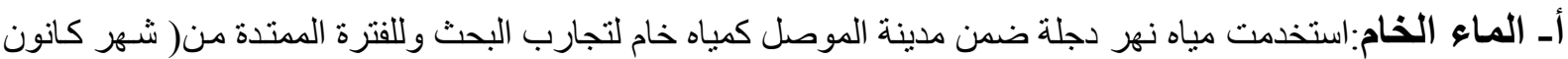

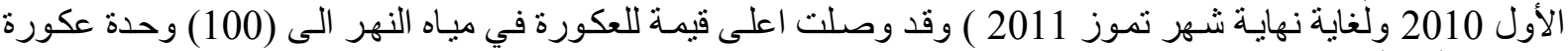

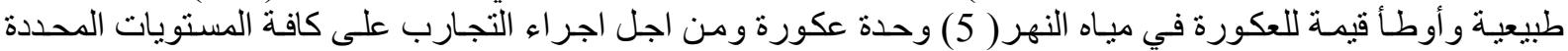

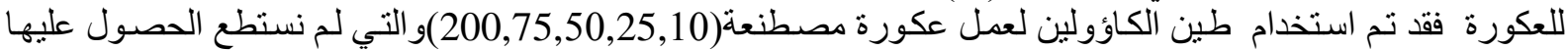

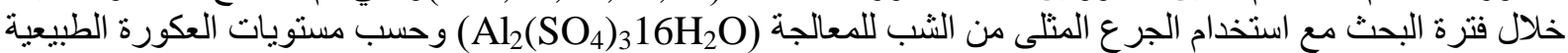
و المصطنعة تم تحضير الثبب على شكل محلول بتركيز (1\%) كما تم استخدام المعدات و الأجهزة ذات العات العاقة مثل قياس

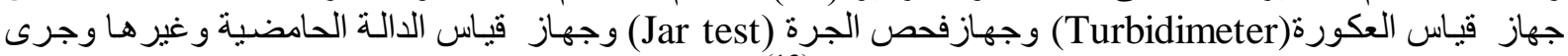
إتباع الطرق القياسية المعتمدة في تحاليل وفحوصات الماء (13).

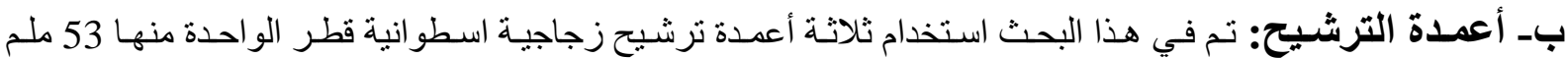

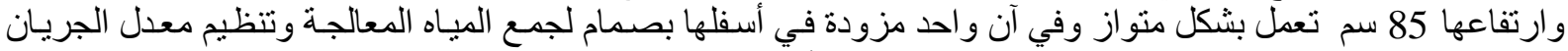

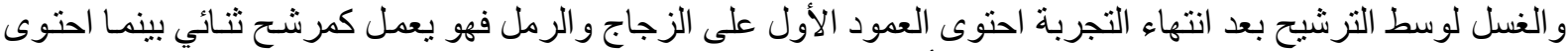

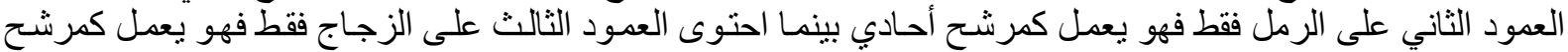

أحادي ايضا.ويوضح الثكلان رقم (1) و (2) صورة فونو غر افية لأعمدة الترشيح المختبرية المستخدمة وخصائصها.

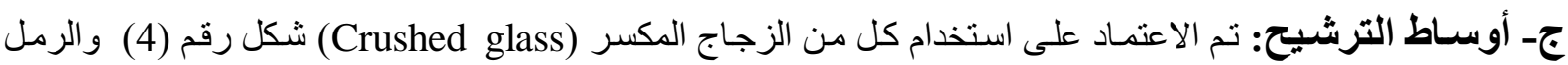

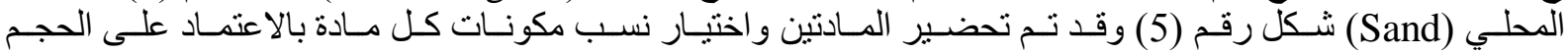
المؤثر(Uffective size) ومعامل الانتظـام (uniformity Coefficient) وحسب التعليمـات الخاصـة بهذا المجـال.تم 


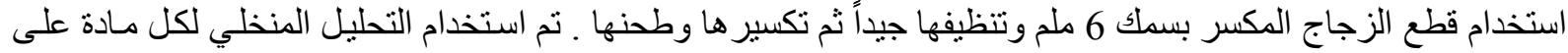

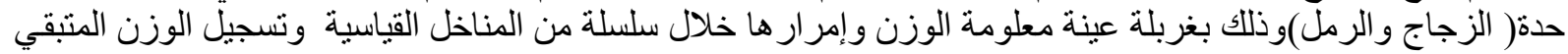

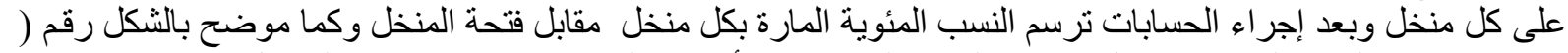

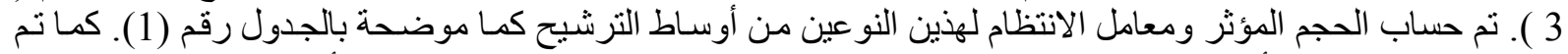
حساب نسبة الامتز اج أو التداخل للمرشح الثنائي (رمل + زجاج) (intermixing) و التـي تنشـأ عندما تكون النسبة بين $.3 \leq \mathrm{D}_{90} / \mathrm{D}_{10}$

D : تمثل حجم الفتحة التي تمر من خلالها كمية من الزجاج تمثل 90٪من وزن النموذج.

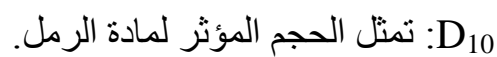

الجدول رقم( 1) ظاهرة الامتز اج في المرشحات الثنائية

\begin{tabular}{|c|c|c|c|c|}
\hline $\begin{array}{c}\text { قيمة الامنز اج } \\
\text { D }_{90} / D_{10}\end{array}$ & $\mathrm{D}_{90}$ & 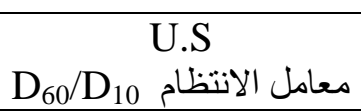 & $\begin{array}{ll} & \text { E.S } \\
\text { D الحجم المؤثر }\end{array}$ & \\
\hline & 2.2 & 2.36 & 0.55 & الزجاج \\
\hline 3.142 & & 2.0 & 0.7 & الرمل \\
\hline
\end{tabular}
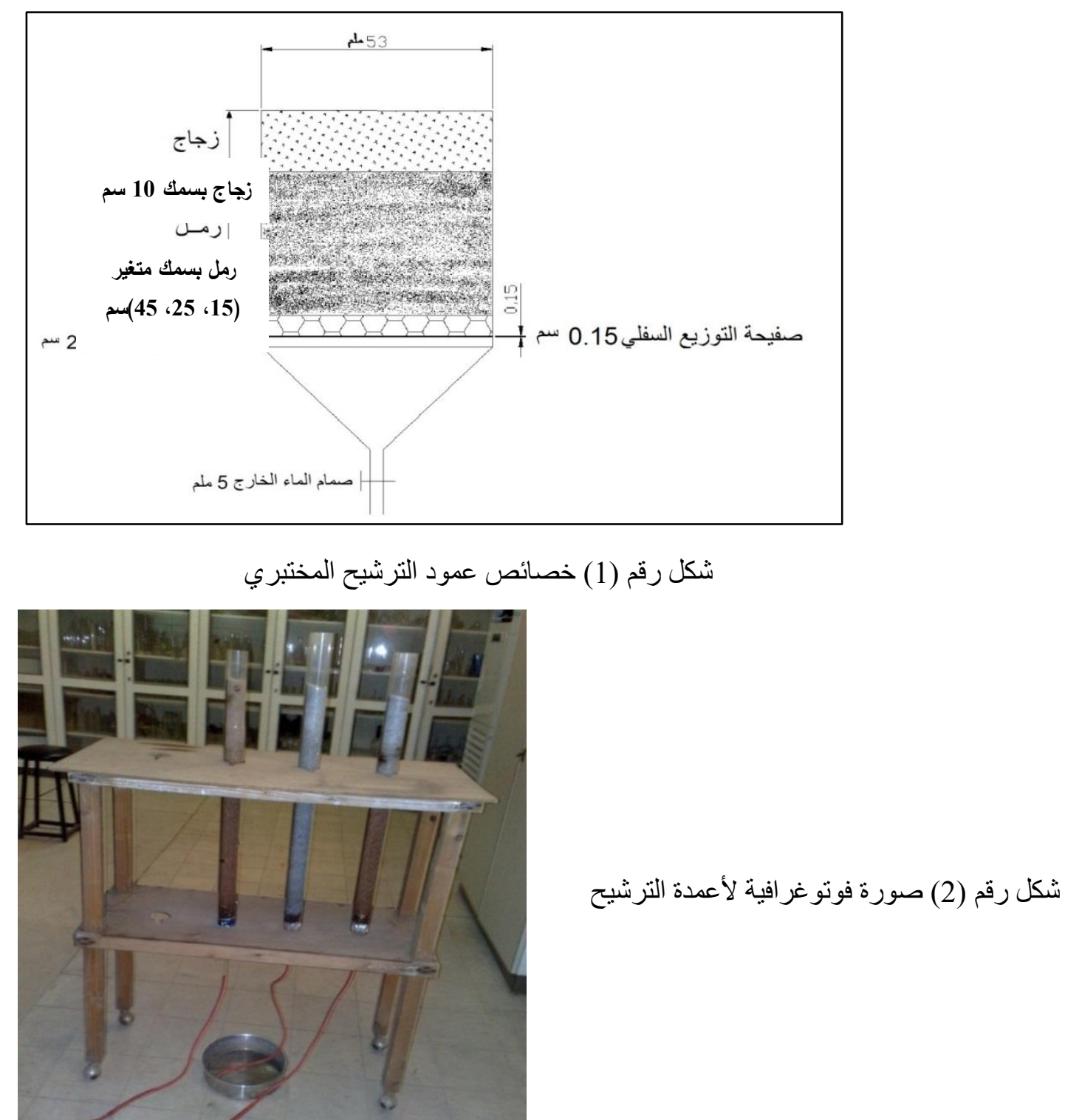
حسن: تقييم أداء مادة الزجاج المكسر ومادة الرمل كوسطي ترشيح في تصفية مياه الثرب

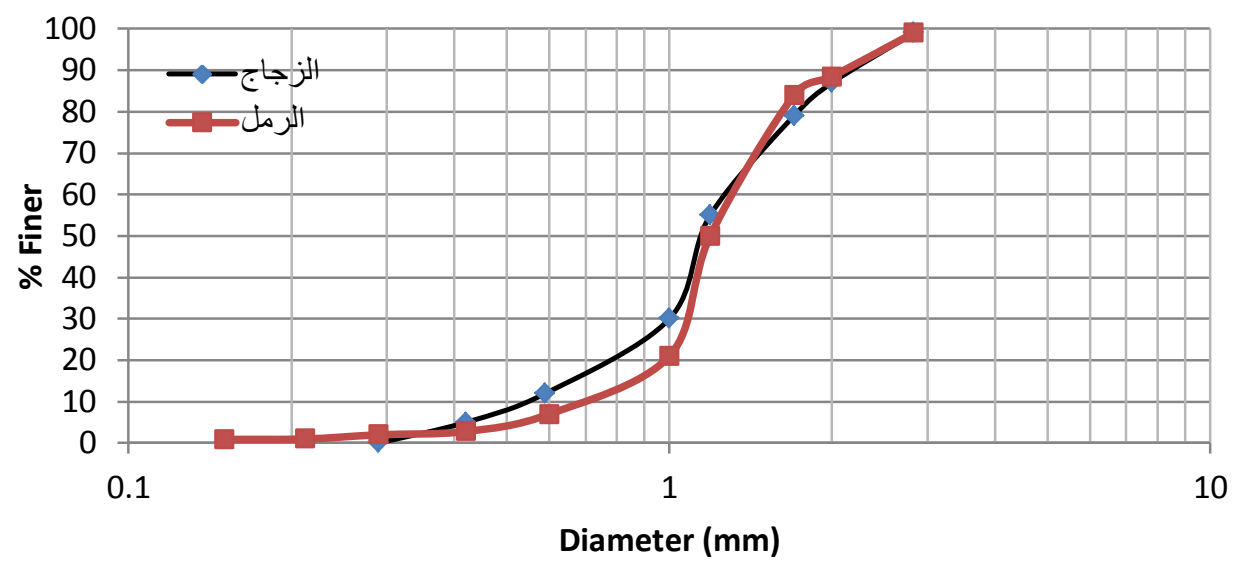

شكل رقم (3) تدرج حبييات الرمل و الزجاج

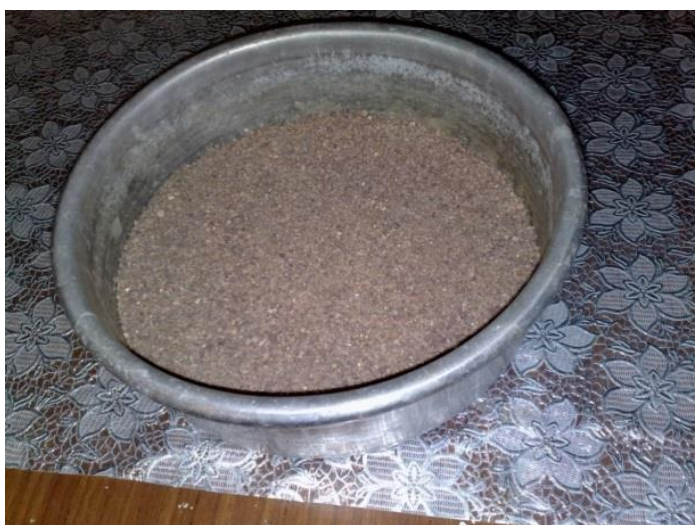

شكل رقم (5) الرمل الاعتيادي

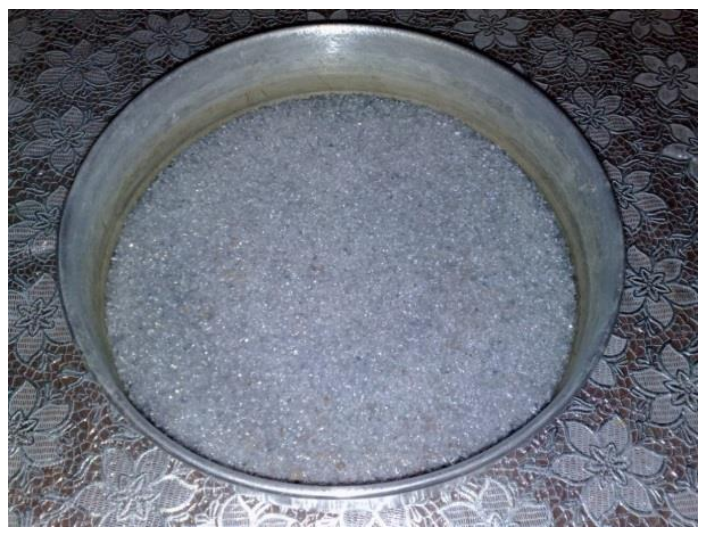

شكل رقم(4) الزجاج المكسر

جدول رقم (2) المتغير ات الداخلة في تصميم البحث ومحددات تشغيلها:

\begin{tabular}{|c|c|}
\hline محددات التشغيل & 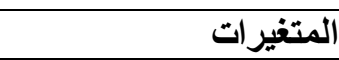 \\
\hline مستويات العكورة الطبيعية و المصطنعة (200,100,75,50,25,10,5 ) & الماءع الخام \\
\hline تراوح مدها بين (14-24)مم & درجة الحرارة \\
\hline 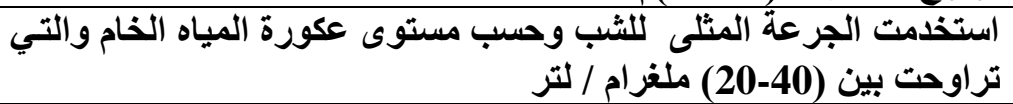 & جرعة المخثر (الشب) \\
\hline تراوحت بين (6.8-8.4) & pH \\
\hline 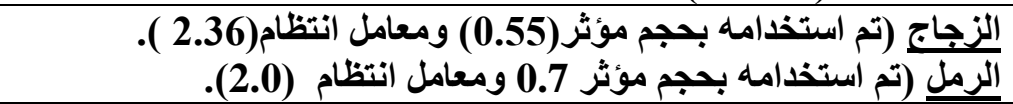 & وسط الترشيح \\
\hline 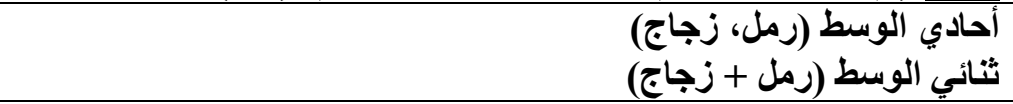 & نوع المرشـح \\
\hline 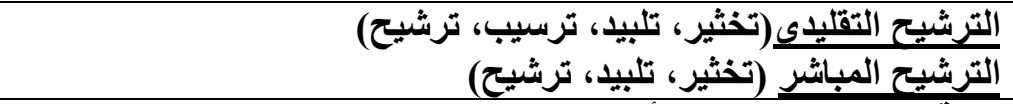 & نمط الترشيح \\
\hline 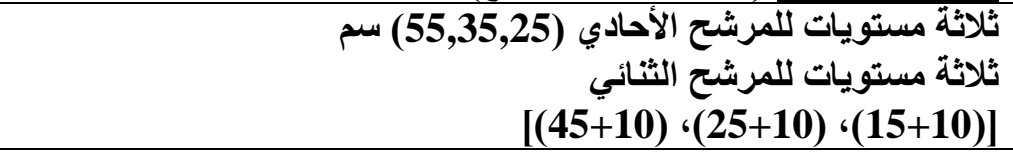 & ، وسط الترشيح \\
\hline
\end{tabular}




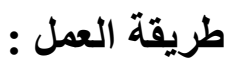

للتحقق من كفاءة أداء مادة الزجاج المكسر كوسط ترشيحي مع مادة الرمل فقد تم تقسيم العمل الى قسمين رئيسين هما 1-تحديد الجرعة المثلى من المادة المخثرة (الثب) باستخدام تجربة فحص الجرة(Jar test) وحسب مستويات العكورة المحددة في الماء الخام أو لا. المان.

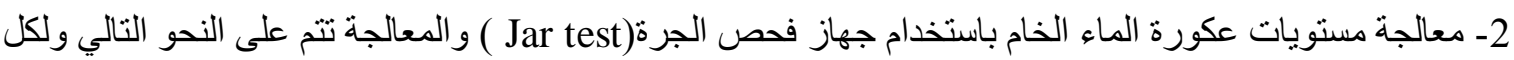
مستو من مسنويات العكورة المحددة(200,75,50,25,10,5) وحدة عكورة: -

وضع لتر واحد من الماء الخام المطلوب معالجته في و عاء كل Jar (ستة أوعية في الجهاز ) وكما موضح بالثكل

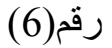

إضافة الجرعة المثلى من المادة المخثرة (الثب) و المحددة مسبقا الى كل و وعاء.

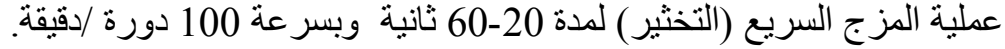

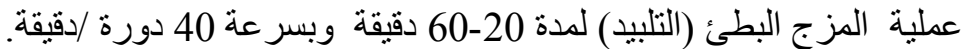

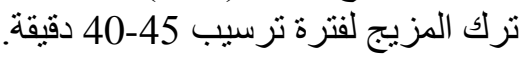
صب كل و عائين من الاوعية الحاوية على الماء الر ائق و المعامل كيمياويا في عمود الترشيح المقابل له (لكل و عائين عمود ترشيح واحد). تجميع المياه المعالجة من كل عمود وبمعدل ترشيح ثابت مقداره ( m/hr 8 م) و إجراء قياسات العكورة النهائية للماء

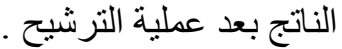

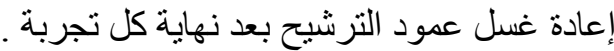

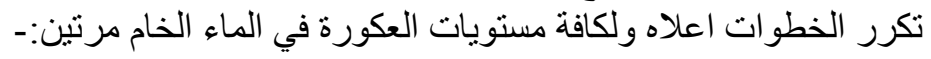

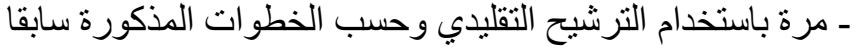

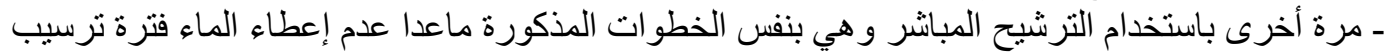
و التحويل مباثرة من التلبيد اللى الترشيح وللتحقق من كفاءة النتائج في الماء الناتج بطريقتي الترشيح (التقلبدي التباءي و المباشر )باستخدام التر اكيب المختلفة من المرشحات.

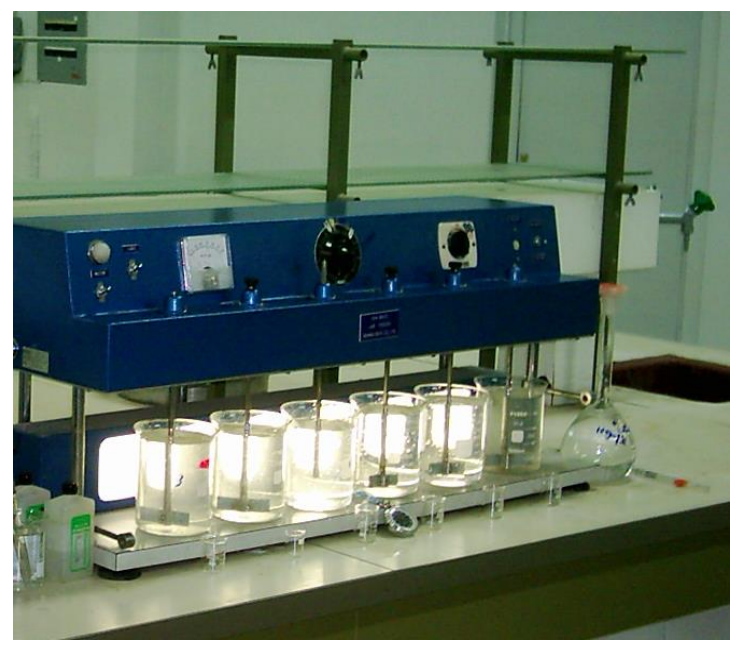

شكل رقم (6) جهاز فحص الجرة (Jar test)

توضح الأشكال من (7-13) النتائج المختبريـة للترشيح المباشر و التي تبين العلاقة بين عمق المرشح و العكورة

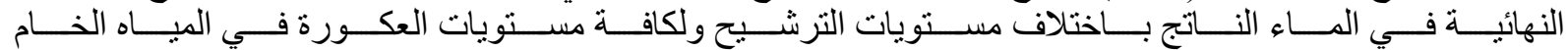
(200,100,75,50,25,10,5) وحدة عكورة.

اذ يبين الثكل رقم (7) العلاقة بين عمق المرشح و العكورة النهائية للماء الناتج باختلاف مستويات الترشيح الثلاثة [(رمل + زجاج)، رمل، زجاج)] و عند عكورة أولية في المياه الخام 200 وحدة عكورة. وقد تراوحت قيم العكورة النهائية 


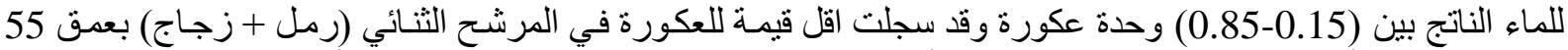

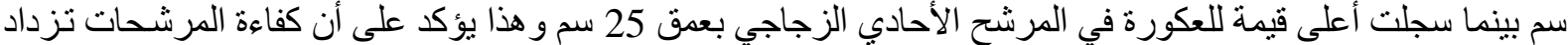

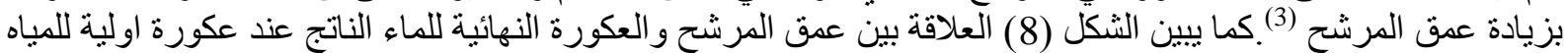
الخام (100) وحدة عكورة وقد نراوحت قيمها في الماء الناتج بين (0.11- 1.0 1.

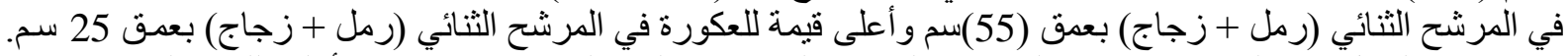

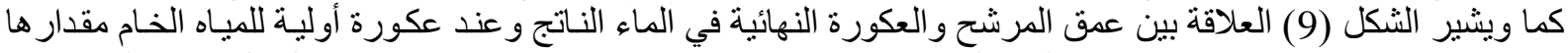

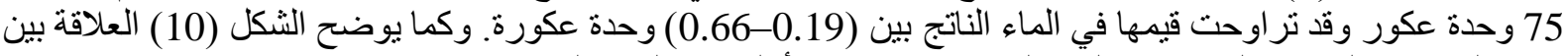

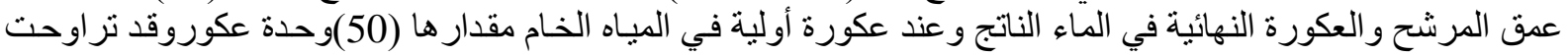

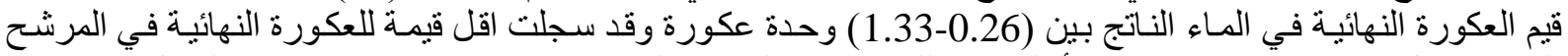

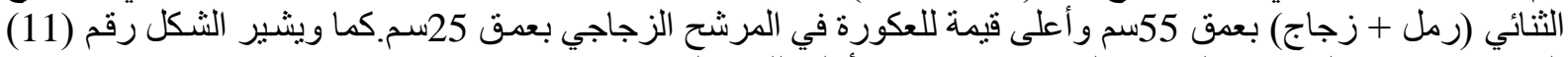

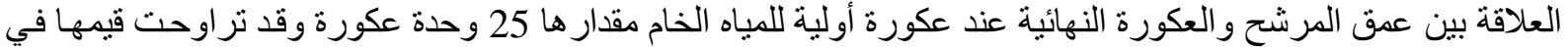

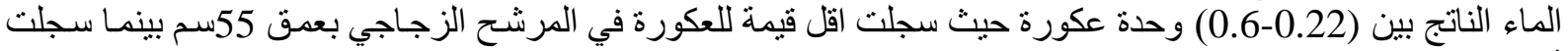

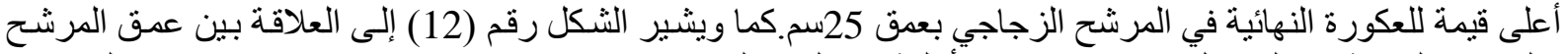

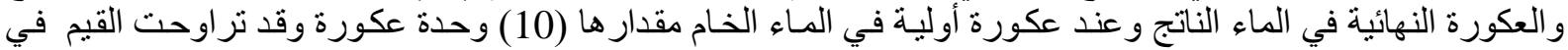

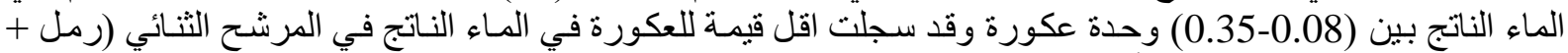

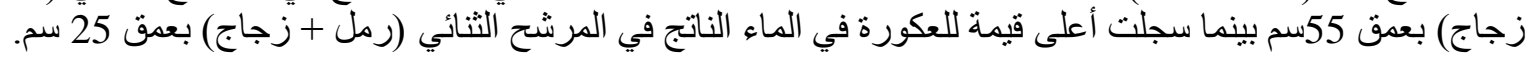

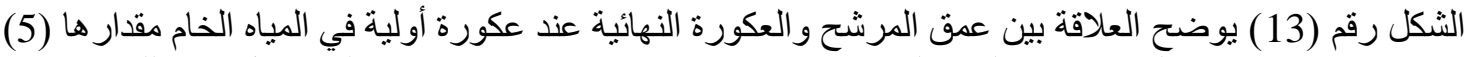

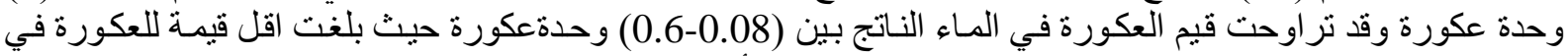

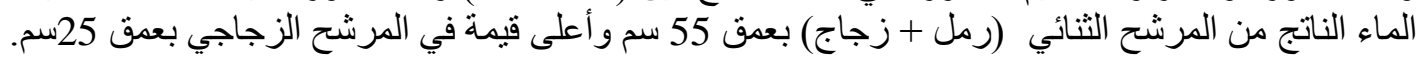

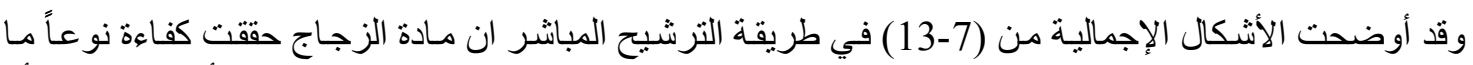

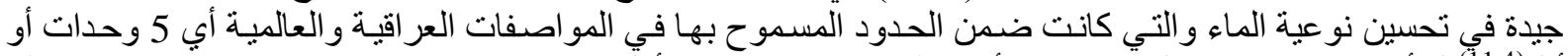

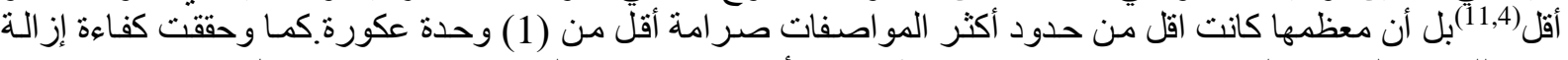

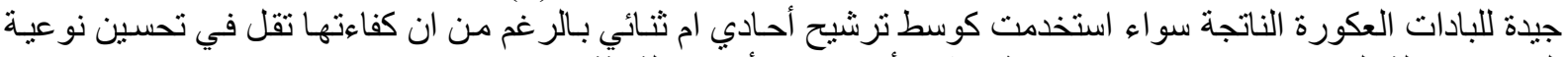
الماء في إز الة العكورة عند استخدامه كوسط ترشيح أحادي وبالأعماق الثناثة (55,35,25)سم ـ

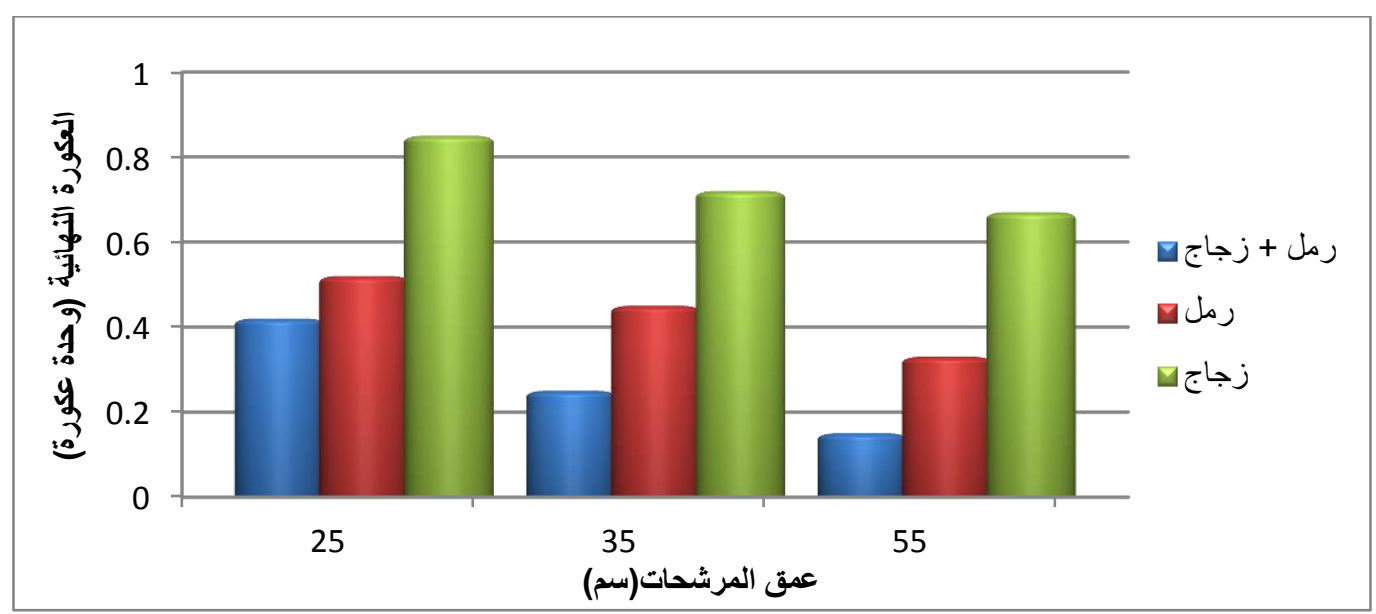

شكل رقم (7 ) في "الترشيح المبانر "العلاقة بين عمق المرشح و العكورة النهائية في الماء الناتج باختلاف مستويات الترشيح عند عكورة اولية في المياه الخام 200 وحدة عكورة. 


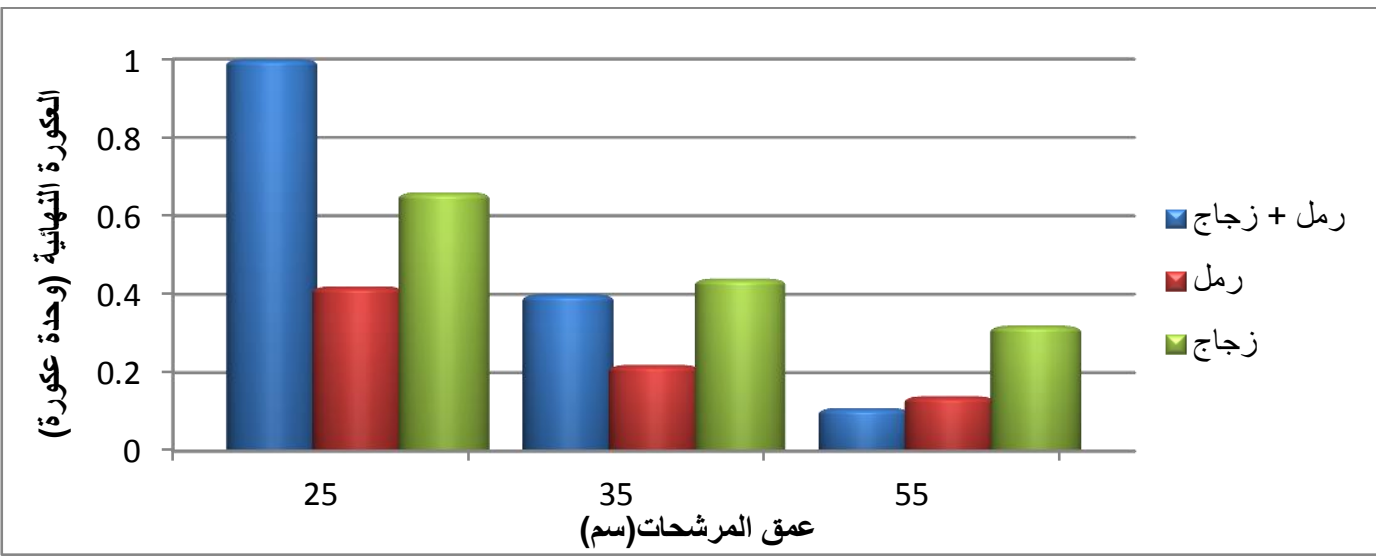

شكل رقم (8) في "الترشيح المباثر "العلاقة بين عمق المرشح و العكورة النهائية في الماء الناتج باختلاف مستويات

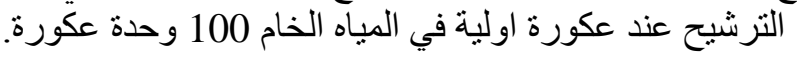

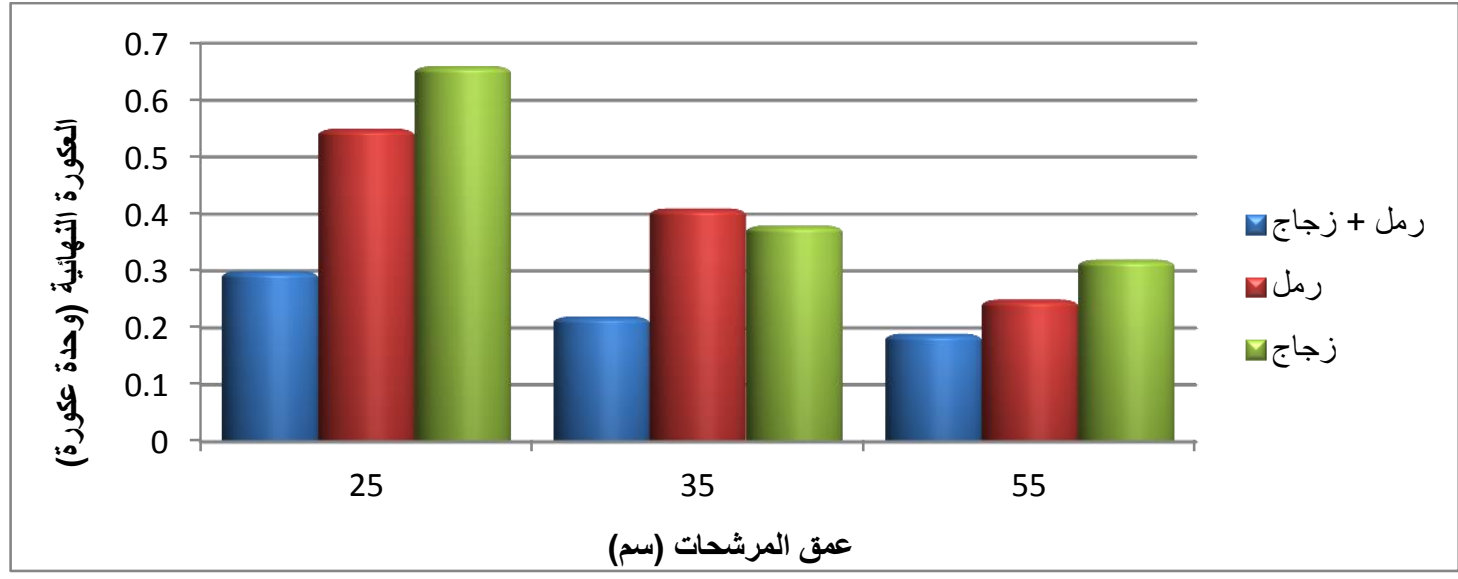

شكل رقم (9) في "الترشيح المباشر "العلاقة بين عمق المرشح و العكورة النهائية في الماء الناتج باختلاف

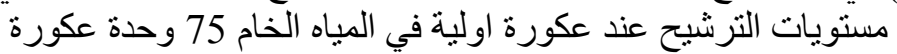

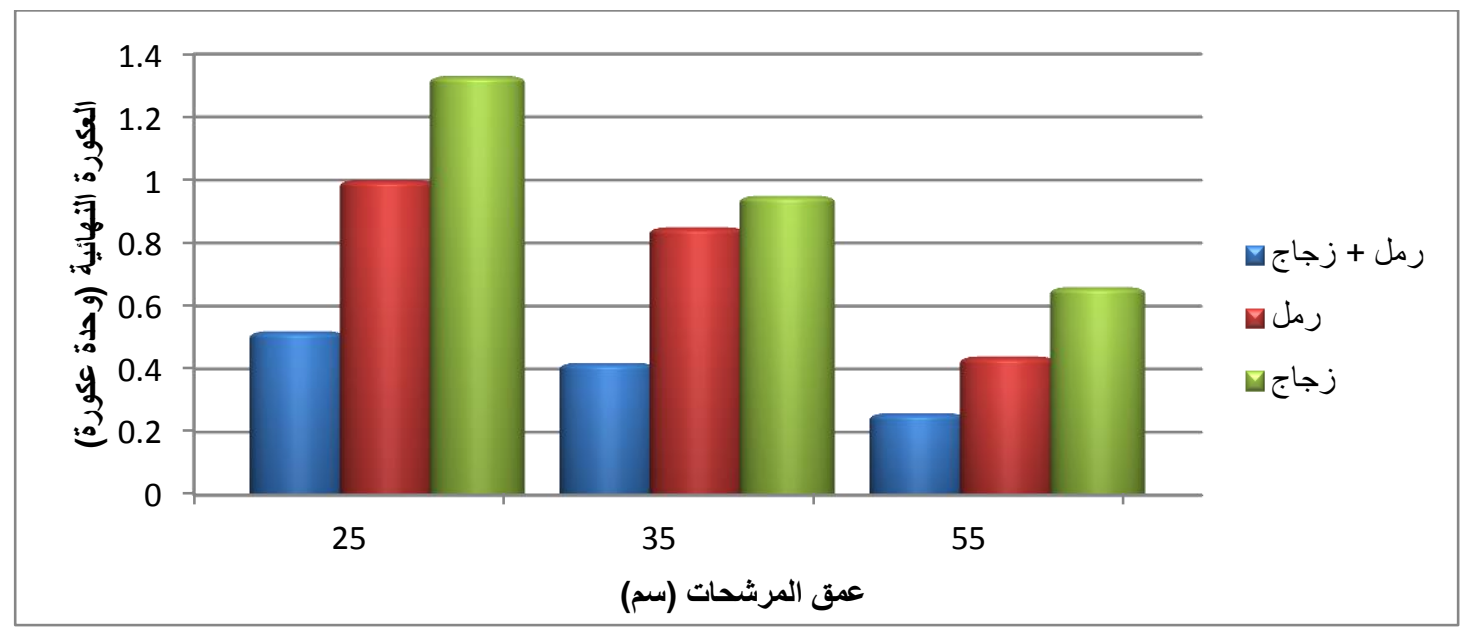

شكل رقم (10) في "الترشيح المباثر" العلاقة بين عمق المرشح و العكورة النهائية في الماء الناتج باختلاف

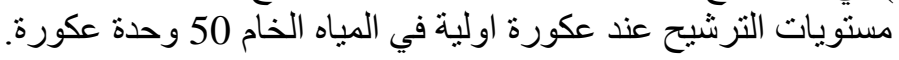


حسن: تقييم أداء مادة الزجاج المكسر ومادة الرمل كوسطي ترشيح في تصفية مياه الثرب

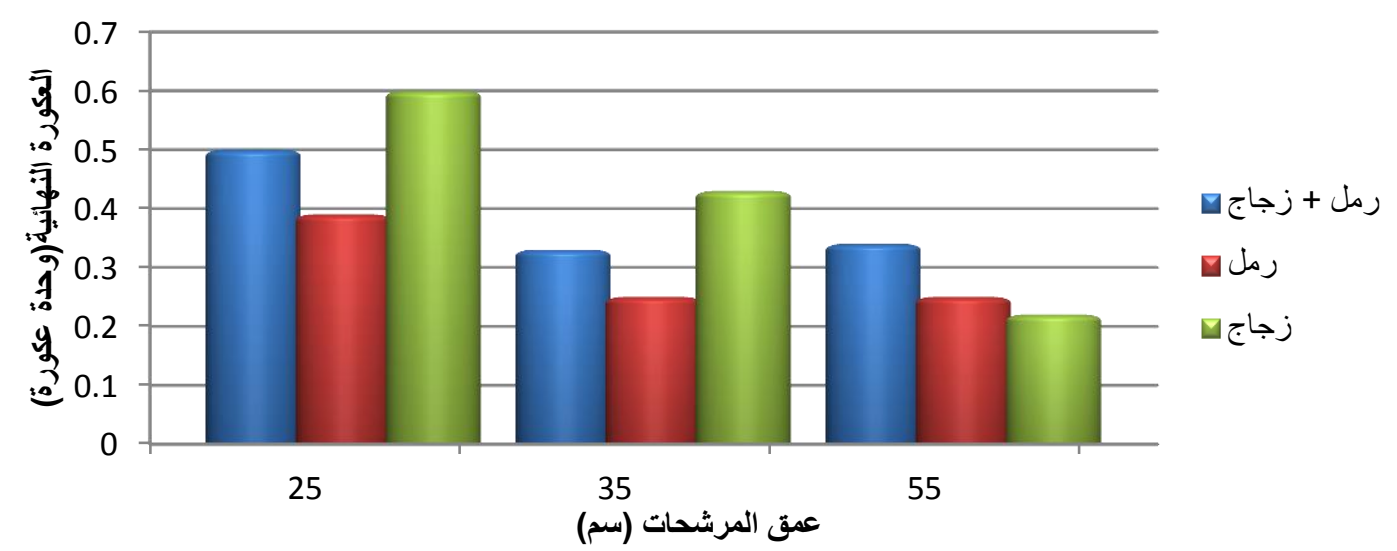

شكل رقم (11)في "الترشيح المباشر"العلاقة بين عمق المرشح و العكورة النهائية في الماء الناتج باختلاف مستويات

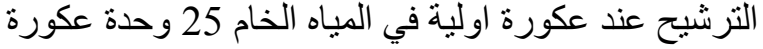

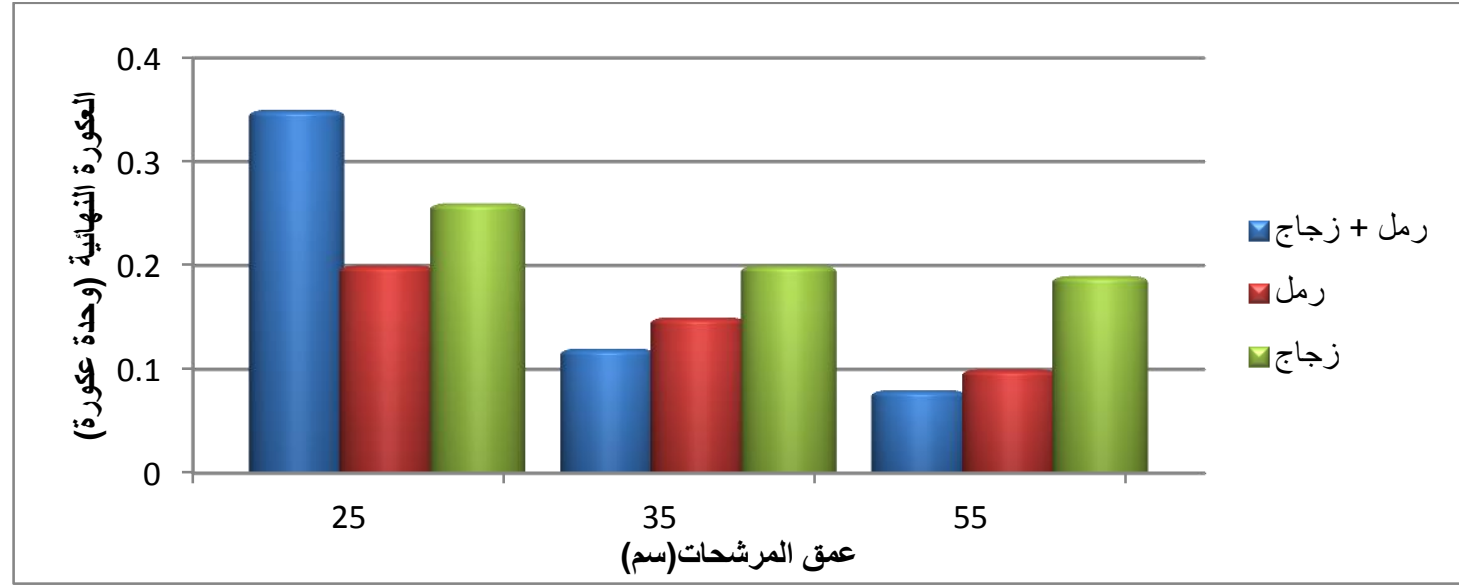

شكل رقم (12) في "الترشيح المباشر "العلاقة بين عمق المرشح و العكورة النهائية في الماء الناتج باختلاف

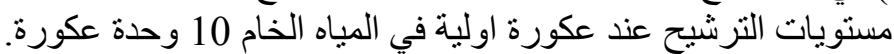

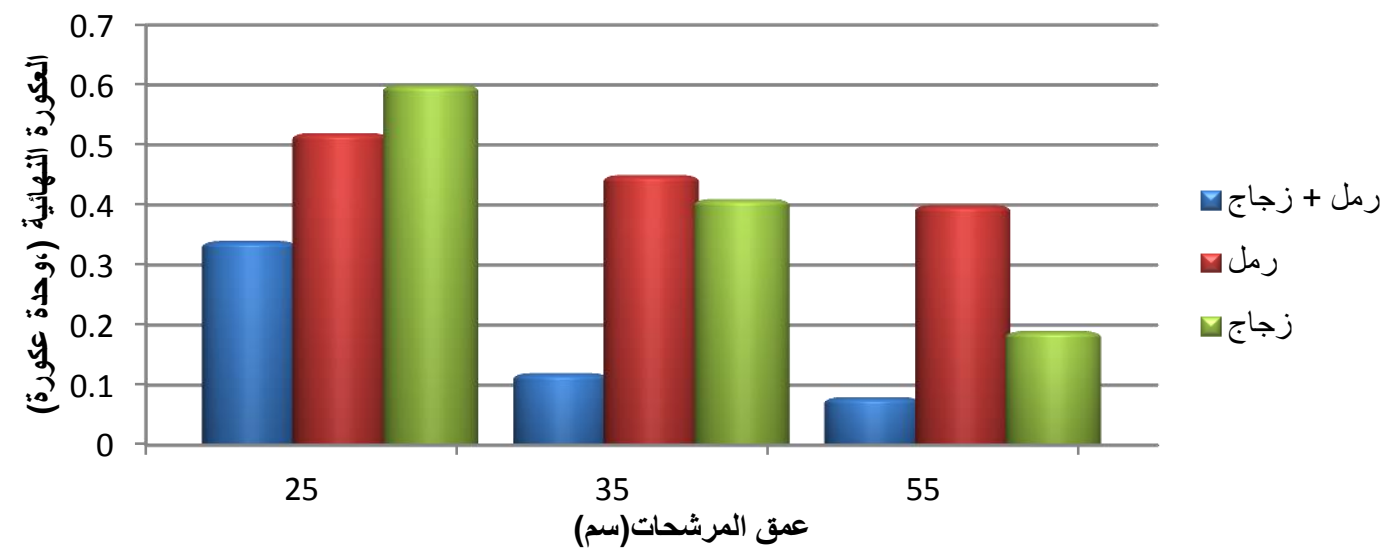

شكل رقم (13) في "الترشيح المباشر "العلاقة بين عمق المرشح و العكورة النهائية في الماء الناتج باختلاف مستويات الترشيح عند عكورة اولية في المياه الخام 5 وحدة عكورة. 


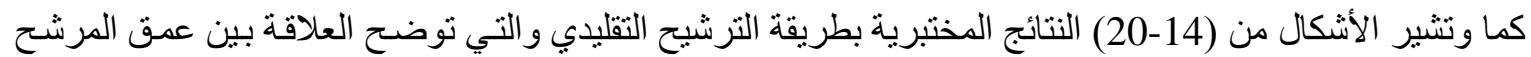

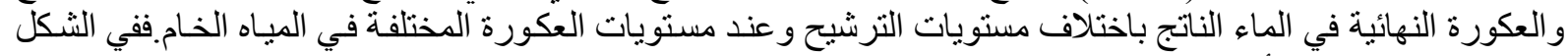

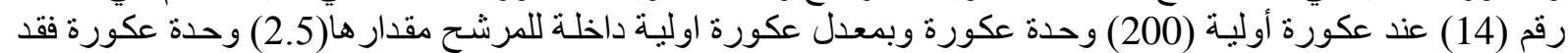

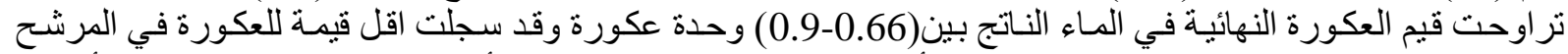

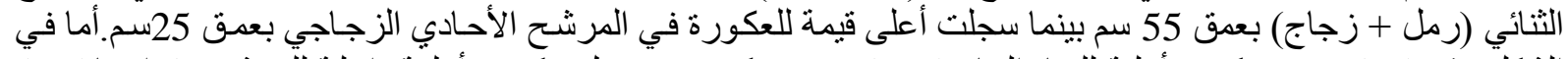

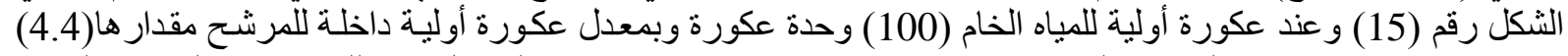

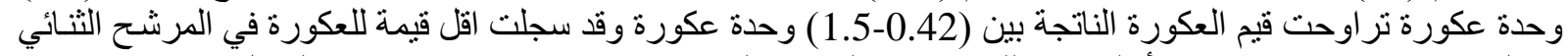

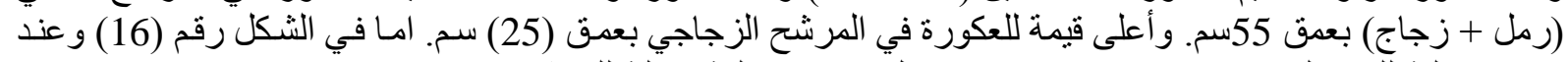

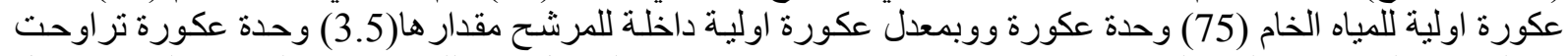

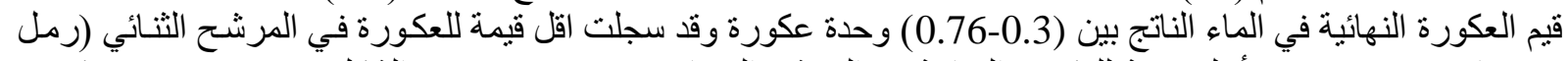

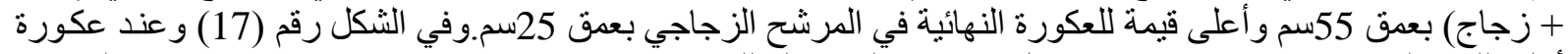

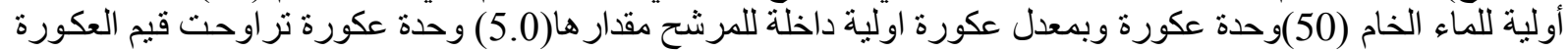

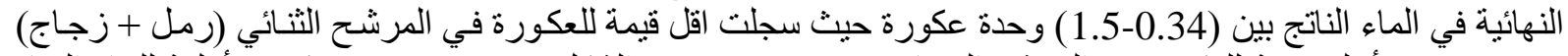

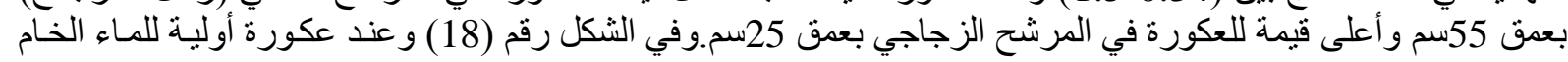

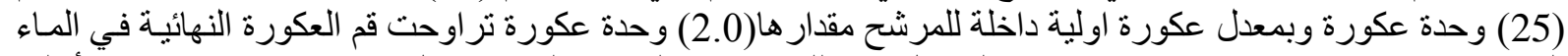

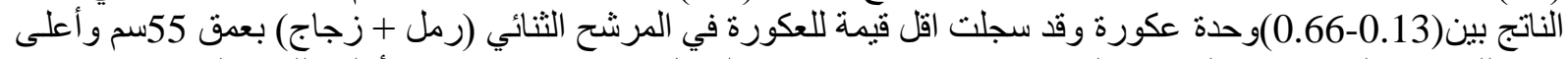

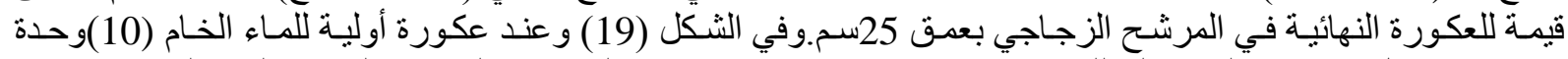

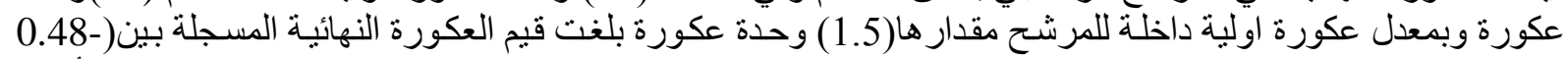

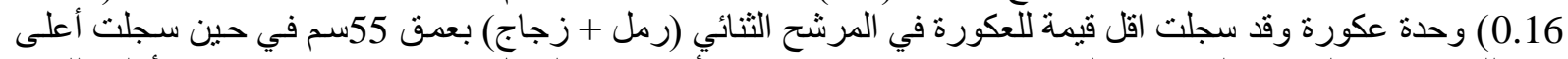

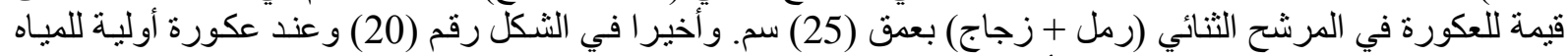

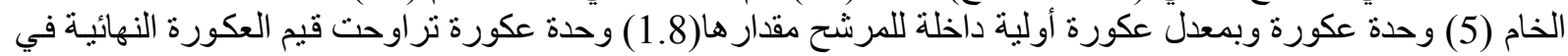

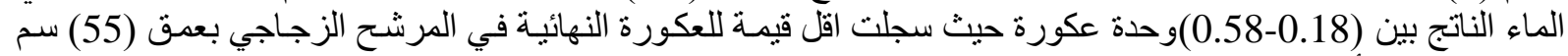
في حين سجلت أعلى قيمة للعكورة النهائية في المرشح الثنائي (رمل + زجاج) بعمق (25)سم.

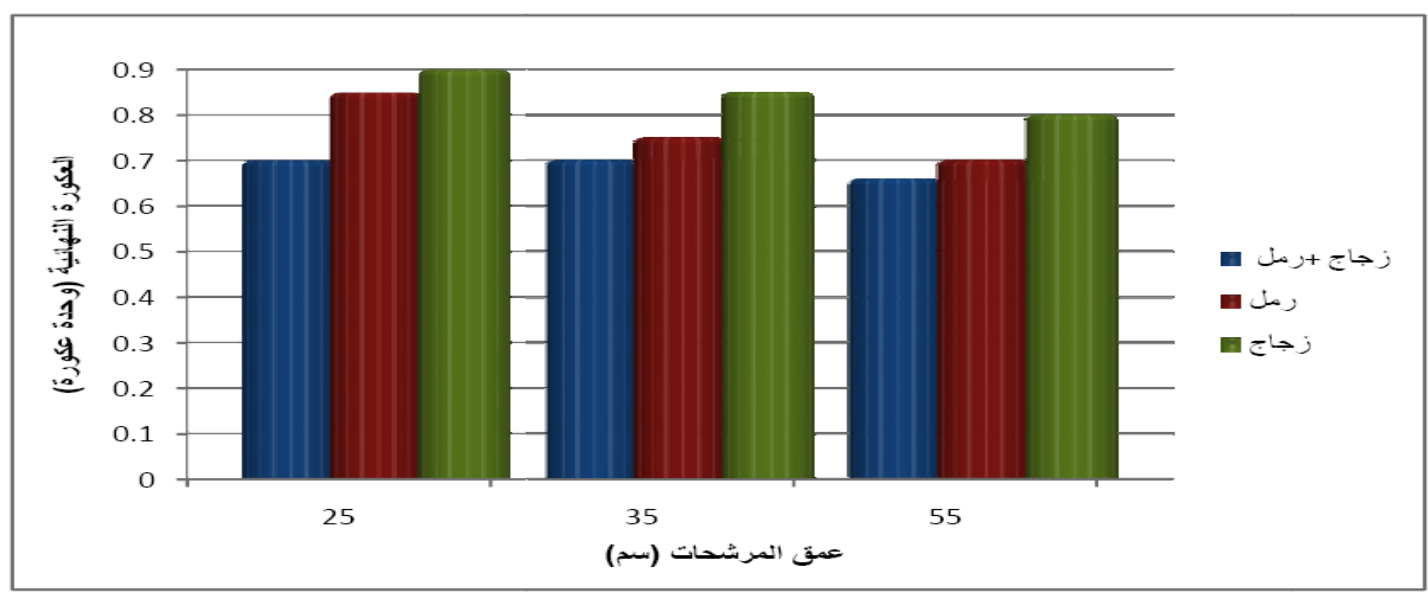

شكل رقم (14) في "الترشيح التقليدي"العلاقة بين عمق المرشح والعكورة النهائية في الماء الناتج باختلاف مستويات الترشيح عند عكورة اولية في المياه الخام 200 وحدة عكورة. 
حسن: تقييم أداء مادة الزجاج المكسر ومادة الرمل كوسطي ترشيح في تصفية مياه الثرب

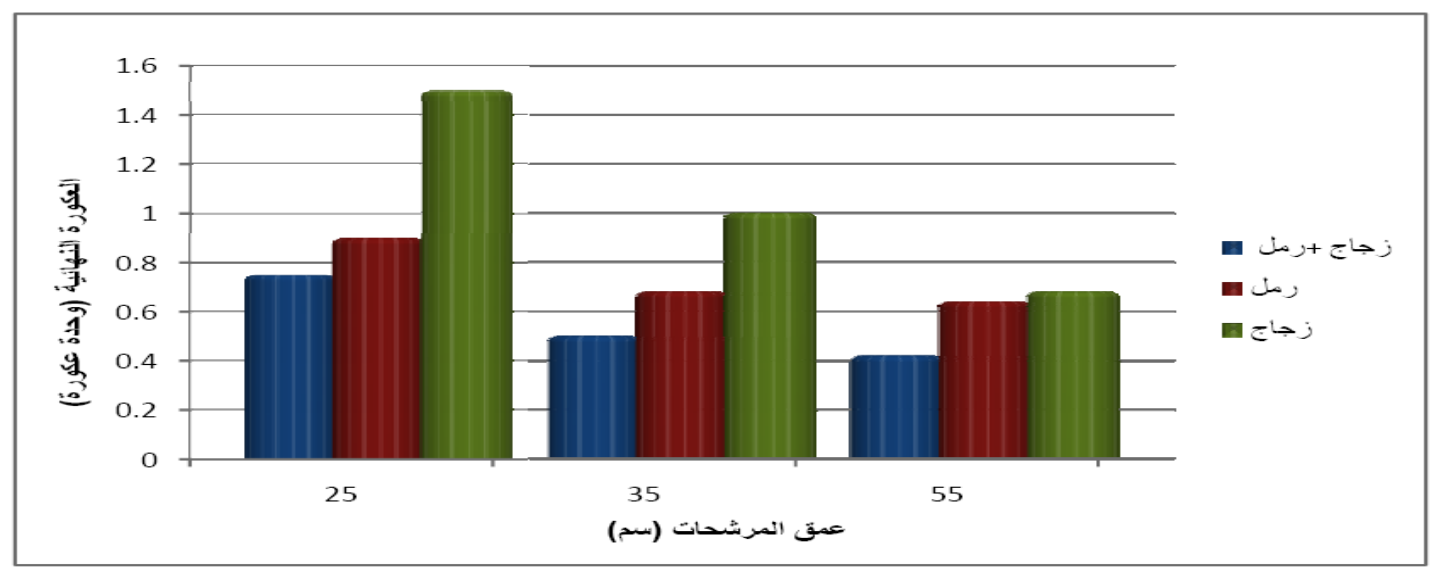

شكل رقم (15)في "الترشيح التقليدي"العلاقة بين عمق المرشح والعكورة النهائية في الماء الناتج باختلاف مستويات الترشيح عند عكورة أولية في المياه الخام 100 وحدة عكورة.

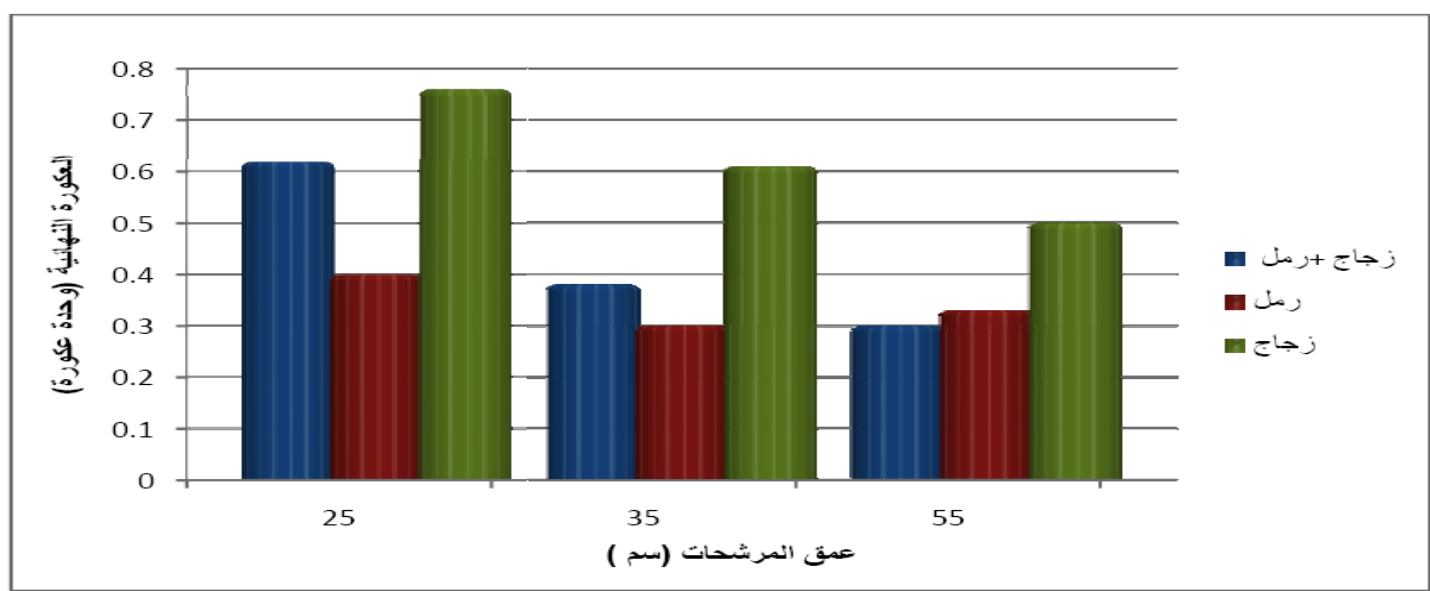

شكل رقم (16) في "الترشيح التقليدي" العلاقة بين عمق المرشح و العكورة النهائية في الماء الناتج باختلاف مستويات الترشيح عند عكورة اولية في المياه الخام 75 وحدة عكورة النئ.

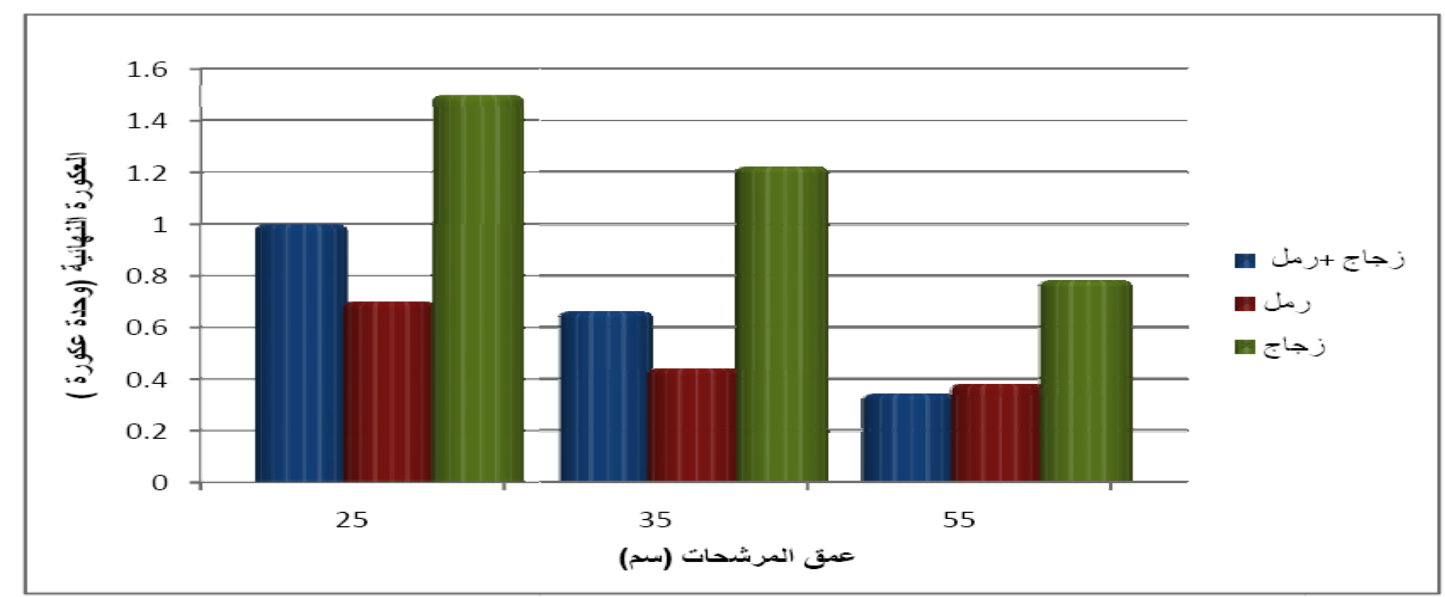

شكل رقم (17)في "الترشيح التقليدي"العلاقة بين عمق المرشح والعكورة النهائية في الماء الناتج باختلاف

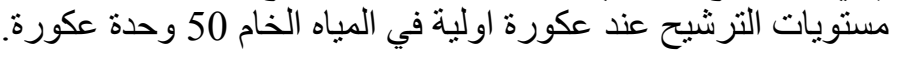




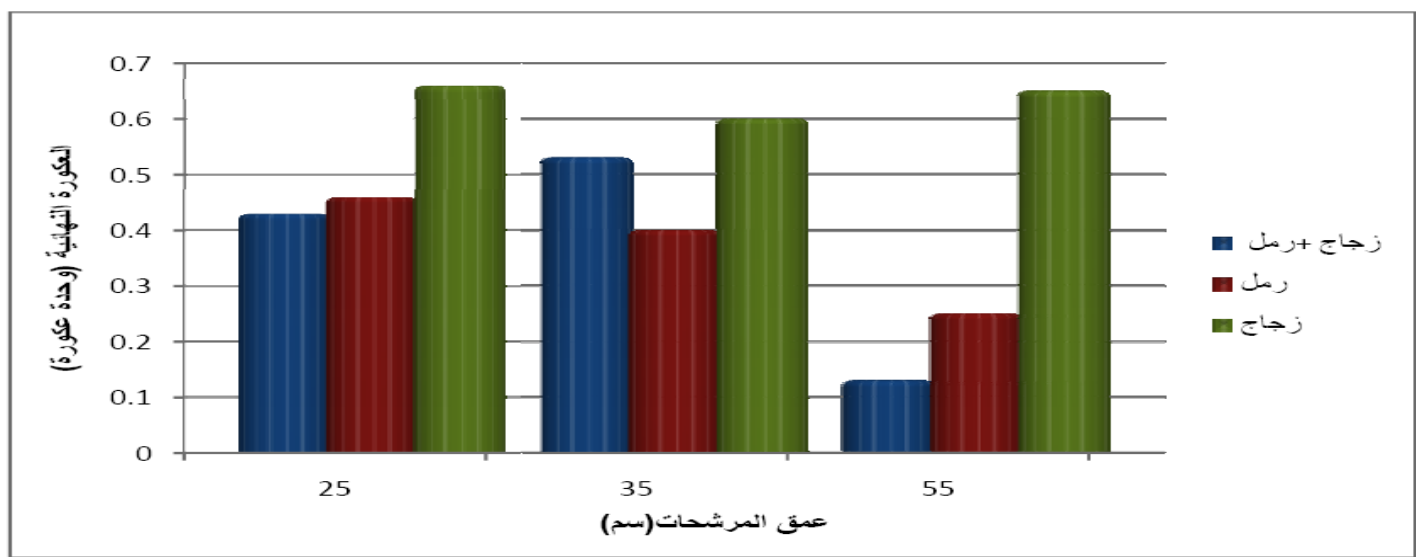

شكل رقم (18) في "الترشيح التقليدي"العلاقة بين عمق المرشح و العكورة النهائية في الماء الناتج باختلاف مستويات الترشيح عند عكورة اولية في المياه الخام 25 وحدة عكورة.

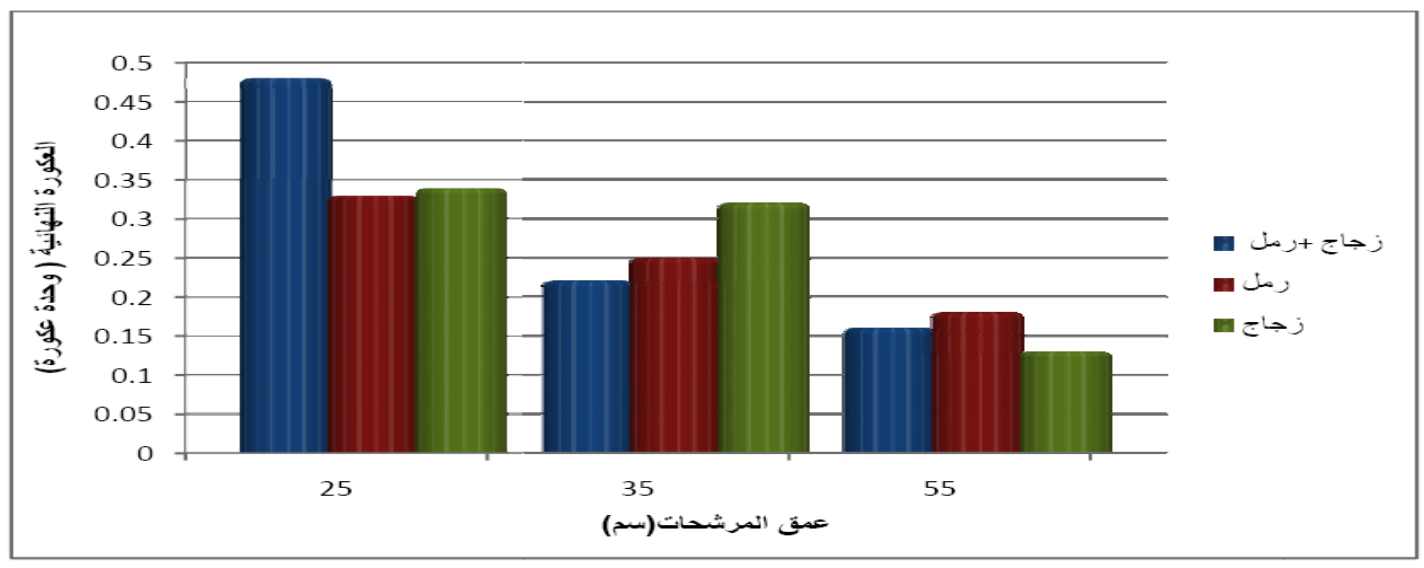

شكل رقم (19) في "الترشيح التقليدي"العلاقة بين عمق المرشح والعكورة النهائية في الماء الناتج باختلاف مستويات الترشيح عند عكورة اولية في المياه الخام 10 وحدة عكورة التئ

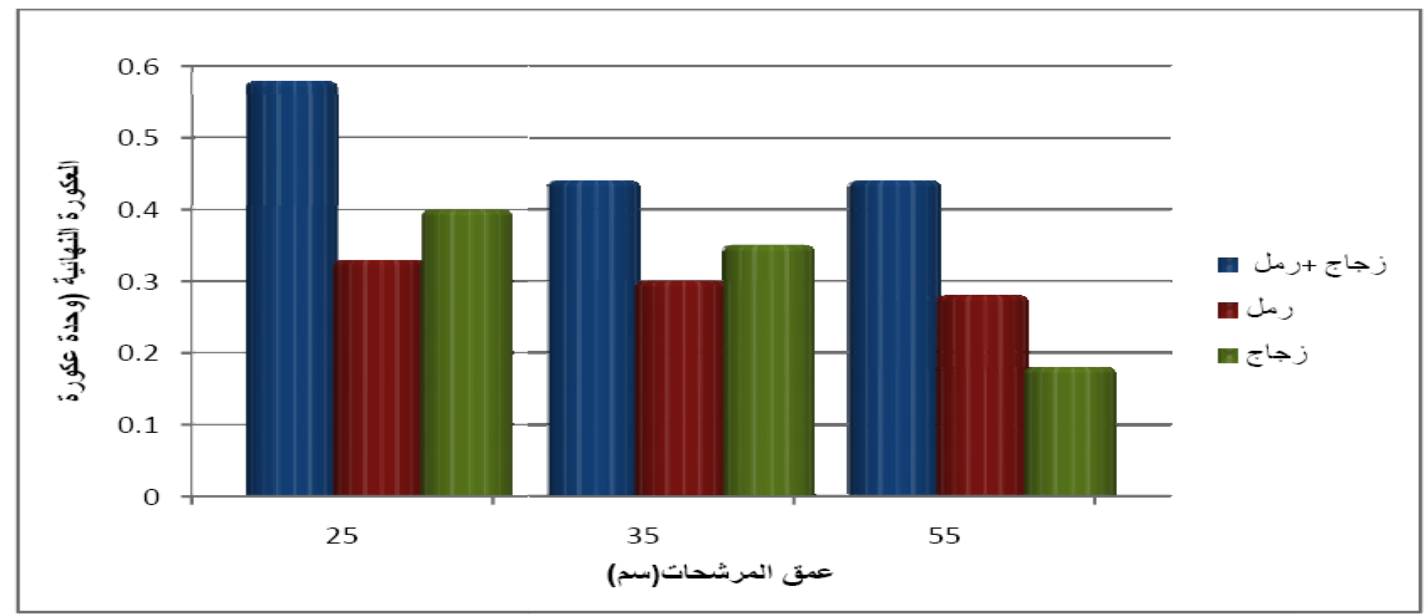

شكل رقم (20) في "الترشيح التقليدي"العلاقة بين عمق المرشح والعكورة النهائية في الماء الناتج باختلاف والتاف مستويات الترشيح عند عكورة اولية في المياه الخام 5 وحدة عكورة. 


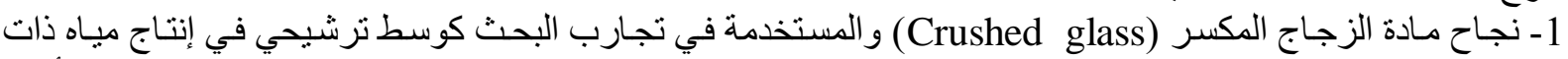

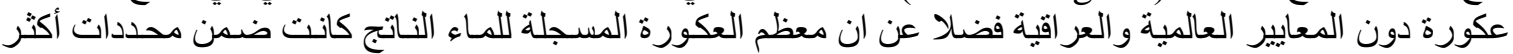

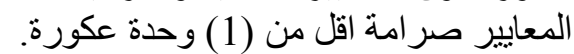

2- تقل كفاءة مادة الزجاج المكسر في إز الة العكورة بكافة مستوياتها عند استخدامها كوسط ترشيح أحادي وبالأعماق الثناثة (55,35,25)

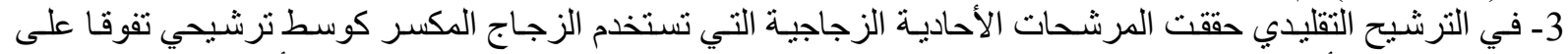

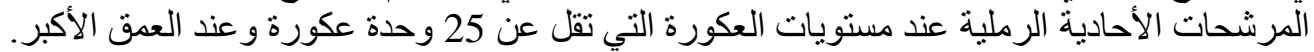

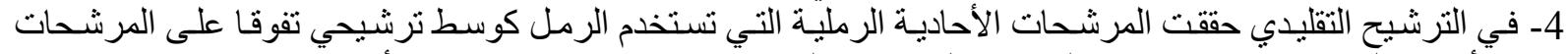

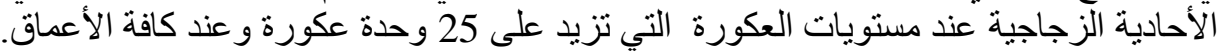

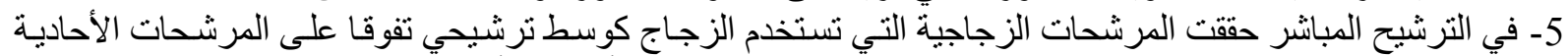

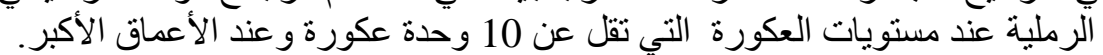

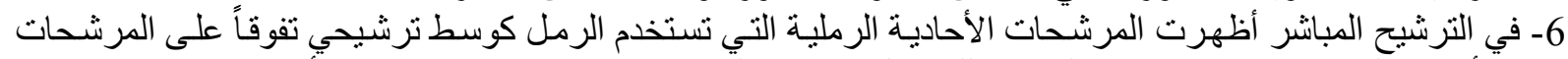

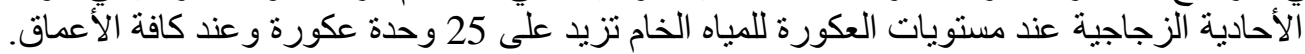

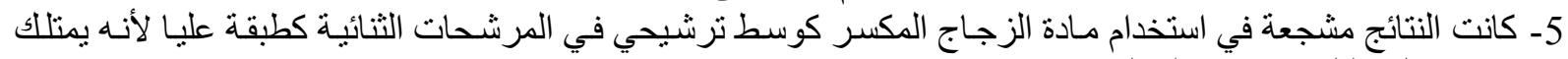

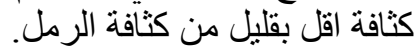

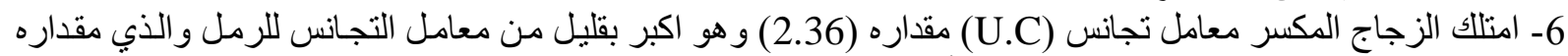

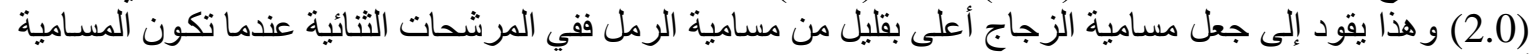

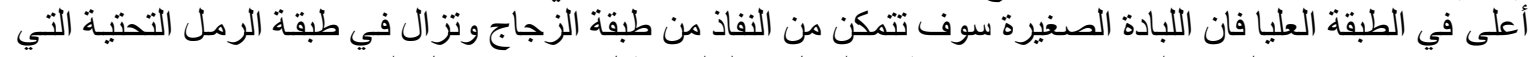

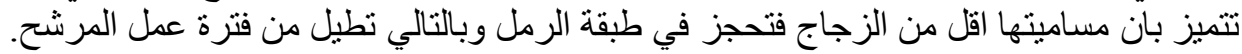

1- إجر اء بحوث أخرى على مادة الزجاج المكسر ضمن إحجام مؤثرة مختلفة (effective size) وتحديد أفضل حجم مؤثر في المرشحات الأحادية والثنائية. 2- دراسة تأثير التغاير في معدل الترشيح على كفاءة مـادة الزجاج المكسر كوسط ترشيحي باستخدام طريقتي الترشيح المباشر و التقليدي.

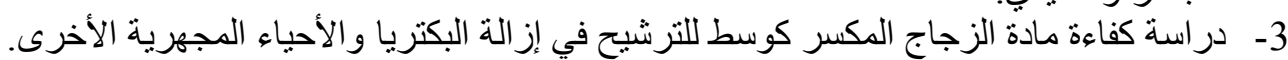

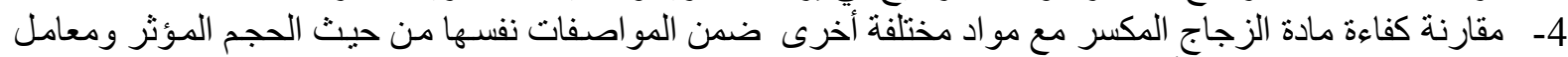
الانتظام في المرشحات الأحادية والثنائية.

1 المصادر الماجد ،عصام محمد (1995) "الهندسة البيئية" دار المستقبل للنشر والتوزيع ، الأردن.

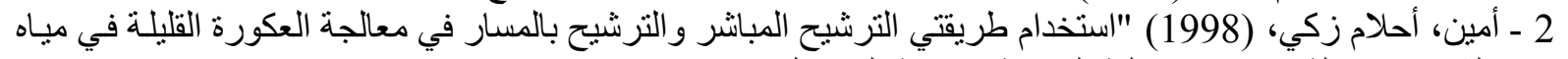

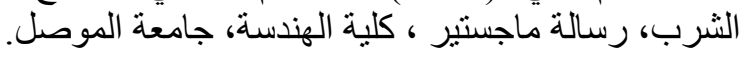

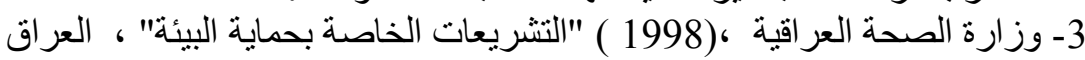

4- Al-Ani,F.H ,(1998)"An Investigation into the use of locally produced Granular activated carbon in treatment of water supplies " Ph.D. ,University of Technology .

5- Rutledge Simon O \&\& Gagnon Graham A.( 2008) "Comparing crushed recycled glass to silica sand for dual media filtration " J.Environ.Eng.Sci.1: (349-358).

6- Simon O. , Fahie Chris \& Gagnon Graham A.( 2002) "Assessment of crushed recycled glass as filter media for drinking water treatment " JCSCE/EWRI of ASCE Environmental Engineering Conf Niagara.

7- Droste,R.L.1997 "Theory and practice of water\& wastewater treatment" JohnWiley\& sons, Inc., New York. 
8- Agbanobi, R.O, (2009)"Using granulated wood charcoal as a filter medium" J.Environ. Qual. 28 (3): 1038-1040.

9- WHO.(2004) "Guidelines for drinking Water quality" Geneva.

10- Suthaker, S., Smith, D.W and Stanley, S.J. (2004) "Evaluation of filter media for upgrading existing filter performance"J.Environ.Technol. 16: (625-643).

11- American Water Work Association (AWWA)( 1999). "Water quality and treatment" McGraw-Hill, Inc, New York.

12- Piccirillo, J.B, and Letterman, R.D. (1997) "Examination of pulverized waste recycled glass as filter media in slow sand Filtration New York state Energy Research and development Authority Albany.

13-APHA,AWWA\&WPCF, (1995) "standard methods for the Examination of water and waste water" $18^{\text {th }}$ ed American Public Health Association Washington, D.C, U.S.A.

14-Culp, R.(1977) "Direct filtration " Jour. AWWA 69:7 ,U.S.A.

15-McCormick ,R.F. and King ,p.H.(1983) " Factors that Affect use of direct filtration in treating surface water "Jour. AWWA 74:5,U.S.A.

16-Kawamura , S. (1995) "Design\& Operation of High Filters J.AWWA 67:10 U.S.A.

17-Prendivile,P.W.,(1983)," Upgrading water filtration plants" ,Civil Engineering 53(10),1983,U.S.A.

18- Craig , K.(1985)" Direct filtration , An Australian Study " ,Jour .AWWA 77:17 , Dec., U.S.A.

$$
\text { تم اجراء البحث في كلية ألهندة = جامعة ألموصل }
$$

